\title{
Kernos
}

Revue internationale et pluridisciplinaire de religion grecque antique

8| 1995

Varia

\section{A. Moreau, Le mythe de Jason et Médée. Le va-nu- pied et la sorcière}

\section{Monique Mund-Dopchie}

\section{(2) OpenEdition \\ Journals}

Édition électronique

URL : http://journals.openedition.org/kernos/620

DOI : $10.4000 /$ kernos.620

ISSN : 2034-7871

Éditeur

Centre international d'étude de la religion grecque antique

Édition imprimée

Date de publication : 1 janvier 1995

Pagination : 312-313

ISSN : 0776-3824

\section{Référence électronique}

Monique Mund-Dopchie, «A. Moreau, Le mythe de Jason et Médée. Le va-nu-pied et la sorcière », Kernos [En ligne], 8| 1995, mis en ligne le 12 avril 2011, consulté le 24 septembre 2020. URL : http:// journals.openedition.org/kernos/620 ; DOI : https://doi.org/10.4000/kernos.620 
Robert Joly, Glane de philosophie antique. Scripta minora, Bruxelles, Ed. Ousia, 1994, 1 vol. $14 \times 21 \mathrm{~cm}, 327$ p. (Coll. Cabiers de philosophie ancienne, 10). ISBN 2-87060-042-9.

Rendre compte ici de cet ouvrage, c'est tout d'abord une manière de s'associer à l'hommage que $\mathrm{L}$. Couloubaritsis a souhaité rendre à son collègue R. Joly, admis à la retraite voici deux ans, en publiant le livre dans la collection qu'il dirige. Professeur aux Universités de Bruxelles et de Mons, l'A. est particulièrement connu pour ses travaux sur le corpus hippocratique et sur la patristique. Les études qui composent ce recueil ne concernent que très marginalement cette importante production, mais sont une sélection de 17 articles qui concernent la pensée antique et qui ont été publiés dans diverses revues, entre 1955 et 1989. Les sujets abordés sont des plus divers et couvrent une longue période allant de Pythagore aux penseurs chrétiens, sans compter $\mathrm{K}$. Popper, convoqué au titre de critique de Platon. Les lecteurs intéressés par l'étude de la pensée religieuse se réjouiront de trouver ici rassemblées une série d'intéressantes contributions dont certaines n'étaient pas toujours aisément accessibles : Les origines de l'homoiôsis theôi (p. 7-14), Vie idéale et apothéose pbilosophique (p. 125-140), L'exbortation au courage (tharrein) dans les mystères (p. 156-163), Note sur la metanoia (p. 164-172); concernant les rapports entre christianisme et paganisme: La spécificité de la morale chrétienne (p. 212-252), Parallèles païens pour Justin, Apologie, I, IX (p. 253265), Sainteté paienne, (p. 266-281), Sur deux thèmes mystiques de Grégoire de Nysse (p. 299-320). Est jointe une bibliographie des livres et des autres articles que l'A. a consacrés à l'étude de la pensée antique.

Une glane qui procure une riche moisson!

A. MOTTE

(Université de Liège)

Alain Moreau, Le mythe de Jason et Médée. Le va-nu-pied et la sorcière, Paris, Les Belles Lettres, 1994. 1 vol. $15 \times 21,5 \mathrm{~cm}, 2$ cartes (Coll. Vérité des Mythes). ISBN : 2-251-32420-8. Prix : $195 \mathrm{FF}$.

Préparé par de nombreux articles, le nouveau livre d'Alain Moreau a tout pour séduire et pour instruire les spécialistes et le public cultivé : il se fonde sur une réflexion approfondie, qui aborde le mythe en général et celui de Jason et Médée en particulier; il s'appuie sur une documentation très vaste - l'exhaustivité est illusoire en cette matière - et il est présenté dans un style clair et de manière très pédagogique.

Après avoir retracé le déroulement du récit en tenant compte du plus grand nombre possible de variantes, Alain Moreau s'attache d'abord à découvrir les origines du mythe. Il démontre que celui-ci est déjà bien vivant au début de la seconde moitié du deuxième millénaire av. J.-C. et qu'on y décèle la trace de rites archaïques, liés à la dysosmie et au culte du soleil. De même, au départ, Médée apparaît comme une Déesse-mère agraire, de type bienveillant, mais 
aussi comme une puissance chthonienne, révélée par des pratiques de magicienne. Face à elle, Jason se présente comme un kouros passant par différentes épreuves d'initiation, qu'il réussit et qui lui valent comme récompense la royauté et un bieros gamos. L'histoire va modifier sensiblement ce schéma primitif, ainsi que le révèle la suite de l'analyse. Le voyage des Argonautes perd son aspect initiatique pour devenir une expédition colonisatrice, vantée quand les cités grecques s'assurent le contrôle commercial du bassin méditerranéen, critiquée amèrement, quand Athènes subit les contrecoups de sa politique impérialiste. Médée perd son aspect de divinité bienfaisante pour devenir une femme mauvaise et une sorcière redoutable; au terme de son évolution, elle retrouve sa puissance primitive, mais elle s'est transformée en puissance du mal. Face à elle, Jason perd son statut héroïque : devenant le protégé d'une femme et non plus d'une déesse, il est de ce fait dégradé et est voué à une déchéance inexorable. Dans une troisième partie enfin, Alain Moreau envisage différentes interprétations globales du mythe qui ont été proposées tantôt par les Anciens eux-mêmes (interprétation rationaliste), tantôt par nos contemporains (interprétations folkloriste, structuraliste, psychanalytique), pour montrer l'éclairage nouveau, mais aussi les limites de ces types de regard.

La lecture de ce livre non seulement affine notre vision du mythe du vanu-pied et de la sorcière, mais apporte de nombreux éléments de réflexions à propos d'œuvres particulières de l'Antiquité. On ne pourra plus aborder désormais l'étude de la Médée d'Euripide, de celle de Sénèque ou des différentes Argonautiques qui sont parvenues jusqu'à nous, sans tenir compte de la synthèse qu'Alain Moreau nous livre sur l'ensemble du mythe. Puisse le succès que rencontrera certainement cette étude le porter à soumettre d'autres légendes grecques à son investigation minutieuse et à son analyse critique et perspicace.

Monique MuND-DOPCHIE (Université Catholique de Louvain)

Alain Moreau (éd.), L'Initiation. I : Les rites d'adolescence et les mystères; II : L'acquisition d'un savoir ou d'un pouvoir. Le lieu initiatique, parodies et perspectives. Actes du colloque international de Montpellier, 11-14 avril 1991, Publications de la Recherche, Université Paul Valéry (Séminaire d'Étude des Mentalités Antiques), Montpellier III, 1992, 2 vol., $14,7 \times 21 \mathrm{~cm}, 326+318$ p. ISBN : 2-905397-45-4.

Les actes du colloque organisé par le Séminaire d'Étude des Mentalités Antiques sous l'égide d'Alain Moreau réunissent quarante communications. Organiser un colloque sur un tel sujet est qualifié par son organisateur « d'aventure dangereuse car rien n'est plus difficile à cerner que le mot "initiation" » (p, 6). C'est pourquoi les communications n'ont été acceptées que dans la mesure où elles pouvaient être intégrées dans l'une des trois catégories 